\title{
Effects of Linoleic Acid on Gut-Derived Bifidobacterium breve DSM 20213: A Transcriptomic Approach
}

\author{
Alice Senizza ${ }^{1}$, Maria Luisa Callegari ${ }^{1,2}{ }^{1}$, Biancamaria Senizza ${ }^{1}$, Andrea Minuti $^{3,4}{ }^{\oplus}$, \\ Gabriele Rocchetti ${ }^{1}$ (D), Lorenzo Morelli ${ }^{1,2}$ and Vania Patrone ${ }^{1,4, *(D)}$ \\ 1 Department for Sustainable Food Process (DiSTAS), Università Cattolica del Sacro Cuore, via Emilia \\ Parmense 84, 29122 Piacenza, Italy; alice.senizza@unicatt.it (A.S.); marialuisa.callegari@unicatt.it (M.L.C.); \\ biancam.senizza@virgilio.it (B.S.); gabriele.rocchetti@unicatt.it (G.R.); lorenzo.morelli@unicatt.it (L.M.) \\ 2 Biotechnology Research Centre (CRB), via Milano 24, 26100 Cremona, Italy \\ 3 Department of Animal Science, Food and Nutrition (DiANA), Università Cattolica del Sacro Cuore, \\ via Emilia Parmense 84, 29122 Piacenza, Italy; andrea.minuti@unicatt.it \\ 4 Nutrigenomics and Proteomics Research Center (PRONUTRIGEN), Università Cattolica del Sacro Cuore, \\ via Emilia Parmense 84, 29122 Piacenza, Italy \\ * Correspondence: vania.patrone@unicatt.it; Tel.: +39-0523-599247
}

Received: 8 October 2019; Accepted: 16 December 2019; Published: 17 December 2019

\begin{abstract}
Bacterial production of conjugated linoleic acid (CLA) has recently received great attention because of the potential health benefits of this fatty acid. Linoleic acid (LA) can be converted to CLA by several microorganisms, including bifidobacteria, possibly as a detoxification mechanism to avoid the growth inhibition effect of LA. In the present in vitro study, we investigated the gene expression landscape of the intestinal strain Bifidobacterium breve DSM 20213 when exposed to LA. Transcriptomic analysis using RNA-seq revealed that LA induced a multifactorial stress response in the test strain, including upregulation of genes involved in iron uptake and downregulation of genes involved in sugar and oligopeptide transport. We also observed reduced transcription of genes involved in membrane and pili biosynthesis. The upregulation of iron uptake was not related to any putative ability of LA to chelate $\mathrm{Fe}^{2+}$, but was somewhat linked to stress response. Furthermore, we demonstrated that LA increased reactive oxygen species (ROS) production in bacterial cells, activating an oxidative stress response. This response was proved by thioredoxin reductase transcription, and was primarily evident among bacteria cultured in the absence of cysteine. This is the first report of the potential mechanisms involved in bacterial LA transport and stress response in B. breve.
\end{abstract}

Keywords: linoleic acid; conjugated linoleic acid; Bifidobacterium breve DSM 20213; transcriptomic analysis; stress response

\section{Introduction}

The omega-6 fatty acid linoleic acid (LA) is a structural component of cell membranes, as well as a precursor of several types of eicosanoids that are involved in important physiological processes. Essential fatty acids, such as LA, can only be obtained through diet, and current regulations mandate that infant formula must contain LA and $\alpha$-linolenic acid (ALA) [1].

Conjugated linoleic acid (CLA) refers to a group of LA isomers that naturally occur in ruminant fats and dairy products, and that have been intensively investigated for their potential health promoting properties [2]. CLA stored in the fat tissue and milk of ruminants constitutes the main source of CLA in the human diet [3]. The isomers most abundantly found in nature are c9,t11-CLA, the intermediates 
produced during the biohydrogenation of linoleic acid to stearic acid (C18:0) by some microorganisms in the rumen [3]. CLA-producing bacteria in rumen have attracted a great deal of interest. Additionally, $\mathrm{c} 9, \mathrm{t} 11-\mathrm{CLA}$ is produced through the conversion of vaccenic acid $(\mathrm{C} 18: 1, \mathrm{t} 11)$ in the mammary gland [4]. A similar pathway has been reported in the human colon, where linoleic acid is converted to vaccenic acid via CLA and, finally, to stearic acid [5].

Numerous bacteria have been reported to metabolize LA into CLA. The ability to convert LA into CLA is strain-specific [2], and CLA producers can be divided into two groups based on the isomer: 9,11 and t10,c12-CLA. Many CLA producers are lactic acid bacteria-in particular, various species of lactobacilli. Within this group of bacteria, the putative linoleate isomerase is reportedly the key gene responsible for the bioconversion of LA into CLA [3], although the mechanism remains unclear.

Among bifidobacteria, which are considered normal commensals of the human gastrointestinal tract, some species exhibit the ability to convert LA into CLA. Raimondi et al. screened 34 B. breve strains, and identified B. breve WC0421 as the major CLA producer [6]. In another study, O'Connell et al. [7] used gas-liquid chromatography (GLC) to investigate the capacity of different bifidobacteria species to convert LA into CLA, and found that B. breve NCFB 2258 was the strain that best converted LA. Both reports elucidated a strain-specific ability to convert LA into CLA. In B. breve, the MCRA protein was identified as a carbon-oxygen lyase family protein that may play a role in catalyzing the first step of CLA production [8]. Conversely, $\mathrm{O}^{\prime} \mathrm{C}$ onnell et al. [7] used an insertional mutation approach and found strong evidence that the $m c r A$ gene was not involved in this process.

It is unclear why bacteria convert LA, but one of the best-supported hypotheses is that CLA production may be a detoxification mechanism adopted by the bacterial cells. Koppová and colleagues [9] have studied rumen bacteria, and reported that the lag phase length is proportional to the fatty acid concentration, and dependent on the LA concentration. Interestingly, a higher number of unsaturated double bounds is associated with a greater inhibitory effect on bacterial cell growth [9]. Moreover, Fontes et al. [10] reported that B. breve NCIMB 702258 grown in the presence of LA in semi-skimmed milk exhibited an altered cell membrane composition.

In the present study, we evaluated the in vitro response to LA exposure of the B. breve strain DSM 20213 (LMG 13208; ATCC 15700; NCTC 11815). This strain was isolated from the infant intestine, and can produce CLA [11]. We investigated the effects of LA on B. breve DSM 20213 using RNA-seq analysis to identify genes that could be involved in the response to LA exposure. Finally, we confirmed and verified our results using chemical and microbiological experiments.

\section{Material and Methods}

\subsection{RNA Extraction and Sequencing}

To explore the strain's behavior in the presence of LA, we performed RNA-seq analysis in triplicate, comparing B. breve DSM 20213 grown in MRS-cys-LA (0.5 g/L) to B. breve DSM 20213 grown in MRS-cys. Bacterial cultures were grown in MRS-cys and MRS-cys-LA to an optical density of 0.7 (log phase) at $600 \mathrm{~nm}\left(\mathrm{OD}_{600}\right)$. Then $10 \mathrm{~mL}$ of culture was centrifuged at $10,000 \times \mathrm{g}$ for $10 \mathrm{~min}$, the supernatant was removed, and the cell pellet was immediately stored at $-80{ }^{\circ} \mathrm{C}$ until use. Samples were processed for total RNA extraction following the acidic-phenol/guanidine-isothiocyanate protocol [12]. RNA was purified using the Direct-zol RNA Miniprep kit (Zymo Research, Irvine, CA, USA) following the manufacturer's instructions. RNA quality check, library construction, and sequencing were performed at BGI (Shenzhen, China) using a BGISEQ-500. RNA-seq data have been submitted to Gene Expression Omnibus (GEO) under the accession number GSE139284.

Under our experimental conditions, we generated about $21.86 \mathrm{M}$ reads per sample, and detected a total of 1887 genes. Prior to downstream analysis, we removed sequencing reads that were low-quality or adaptor-polluted, or that had a high content of unknown bases $(\mathrm{N})$. After filtering the reads, the clean reads were mapped to the reference genome using HISAT [13]. The average proportion of reads mapped was $88.37 \%$. The mapping results for each sample were highly uniform, such that the samples 
were comparable. Clean reads were progressively mapped to reference transcripts using Bowtie2 (http://bowtie-bio.sourceforge.net/bowtie2/index.shtml), and the gene expression level in each sample was measured using RSEM [14]. Based on the gene expression levels, we identified the differentially expressed genes (DEGs) between the samples. These DEGs were used to perform a Kyoto Encyclopedia of Genes and Genomes (KEGG) pathway classification and functional enrichment.

\subsection{Real-Time Quantitative PCR Analysis}

To confirm the gene expression profile obtained by RNA-seq, we performed real-time PCR (RT-qPCR) analysis. We reverse transcribed $1 \mu \mathrm{g}$ RNA using the iScript ${ }^{\mathrm{TM}}$ Advanced cDNA Synthesis Kit (BioRad, Hercules, CA, USA) following the manufacturer's directions, and diluted the cDNA 1:10 in nuclease-free water. Then q-PCR amplifications were performed using $5 \mu \mathrm{L}$ of 1:10 diluted cDNA and the KAPA SYBR ${ }^{\circledR}$ FAST qPCR Master Mix (2X) Kit (Kapa Biosystems, Wilmington, MA, USA) in a LightCycler ${ }^{\circledR} 480$ Instrument II (Roche Diagnostics, Indianapolis, IN, USA). Each sample was analyzed in triplicate. Ct values were normalized using the housekeeping gene $r e c F$, as previously described [15]. The utilized primers are reported in Table 1.

Table 1. Oligonucleotide primers used for q-PCR analysis.

\begin{tabular}{|c|c|c|c|}
\hline \multirow{2}{*}{ Gene (Locus Tag) } & \multicolumn{2}{|c|}{ Primers Sequence $\left(5^{\prime} \rightarrow 3^{\prime}\right)$} & \multirow{2}{*}{ Product Size (bp) } \\
\hline & Forward & Reverse & \\
\hline $\operatorname{recF}\left(B B R E \_0834\right)$ & GCACGCATCAATTCAGGAAC & GTCTTCAGGAGTAAACGAAAC & 80 \\
\hline $\begin{array}{l}\text { Cystathionine beta-lyase } \\
\text { (BBRE_1404) }\end{array}$ & TGACCAATCCACTGCTCAAG & GCCAACACACCACCCAAAC & 264 \\
\hline $\begin{array}{l}\text { Permease protein of } \mathrm{ABC} \\
\text { transporter system } \\
\left(B B R E \_1006\right)\end{array}$ & CGCAGCAGATGAATGAGGAG & CCACCCAGTGATGATTGAGG & 245 \\
\hline $\begin{array}{l}\text { ATP-binding Mrp-like } \\
\text { protein }\left(B B R E \_1432\right)\end{array}$ & ACCAACCAGATCAACGGTGC & GCGGCAGAGAGAATCCATAG & 294 \\
\hline $\begin{array}{l}\text { Thioredoxin reductase } \\
\text { (BBRE_1224) }\end{array}$ & CATTAACCATTGGCGGCCTG & GCTGACCACATCGGCAATGA & 164 \\
\hline Lex A (BBRE_0527) & CGACTCCACATCGACGAAC & GCGTTCATGCGAATAAAGCC & 133 \\
\hline $\begin{array}{c}\text { Secreted protein } \\
\text { probably involved in } \\
\text { iron uptake (BBRE_1003) }\end{array}$ & CGCCAAGAAGGACGATTCAG & TTCACGGTCAGGTCAGGAAC & 281 \\
\hline $\begin{array}{l}\text { Ferredoxin-NADP } \\
\text { reductase (BBRE_0908) }\end{array}$ & GTGACTGAATCTGAGAACACT & GATATCGGATGAGTAGACGC & 77 \\
\hline
\end{tabular}

\subsection{Chemicals, Strain, and Culture Conditions}

Linoleic acid was purchased from Sigma-Aldrich (St. Louis, MO, USA). The B. breve DSM 20213 strain was acquired from the DSMZ collection (Braunzschweig, Germany), and was cultured in an anaerobic chamber (Don Whitley Scientific, Bingley, West Yorkshire, UK) at $37^{\circ} \mathrm{C}$ using MRS broth (BD Difco ${ }^{\mathrm{TM}}$ Lactobacilli MRS broth, Thermo Fisher Scientific, Waltham, MA, USA) with the addition of $0.5 \mathrm{~g} / \mathrm{L}$ L-cysteine-HCl (MRS-cys). MRS-cys-LA broth was prepared by adding $0.5 \mathrm{~g} / \mathrm{L}$ LA to MRS-cys.

\subsection{Growth of B. breve DSM 20213 at Different Cysteine Concentrations}

B. breve DSM 20213 was grown overnight (18 h) under anaerobic conditions in MRS-cys. We then used $500 \mu \mathrm{L}$ of the overnight culture to inoculate $(1 \% v / v) 50 \mathrm{~mL}$ fresh MRS medium, with final cysteine concentrations of $0.5 \mathrm{~g} / \mathrm{L}, 0.250 \mathrm{~g} / \mathrm{L}, 0.125 \mathrm{~g} / \mathrm{L}$, and $0 \mathrm{~g} / \mathrm{L}$. To test the protective effect of cysteine against LA, we prepared the previously described samples with and without the addition of $0.5 \mathrm{~g} / \mathrm{L}$ LA in the medium. The strain grown in MRS-cys was used as the control. This experiment was conducted at $37^{\circ} \mathrm{C}$ under anaerobic conditions. Using a spectrophotometer, we measured the $\mathrm{OD}_{600}$ hourly for $16 \mathrm{~h}$. 


\subsection{Growth of B. breve DSM 20213 in Iron Salts-Supplemented Medium}

The overnight culture of B. breve DSM 20213 was used to inoculate $50 \mathrm{~mL}$ of MRS-cys ( $1 \% v / v)$ supplemented with $50 \mathrm{mM}$ ferric citrate, $50 \mathrm{mM}$ iron sulfur, or a combination of both (1:1), to investigate the role of iron in LA metabolization. Samples were prepared with and without the addition of $0.5 \mathrm{~g} / \mathrm{L}$ LA. The strain grown in MRS-cys was used as the control. A spectrophotometer was used to measure the $\mathrm{OD}_{600}$ hourly up to $15 \mathrm{~h}$, and every $10 \mathrm{~h}$ thereafter.

\subsection{Thiobarbituric Acid Reactive Substance (TBARS) Assay}

We performed the TBARS assay to quantify the lipid peroxidation marker malondialdehyde (MDA), according to the method reported by Zhang and Huang [16], with minor modifications. Briefly, $10 \mathrm{~mL}$ of cell culture was centrifuged for $10 \mathrm{~min}$ at $10,000 \times \mathrm{g}$. The pellet was then mixed in a tube with $1 \mathrm{~mL} 0.1 \%$ trichloroacetic acid (TCA), and placed in an ultra-sonic bath at room temperature for $3 \mathrm{~min}$ to promote extraction. Next, the tube was centrifuged $\left(10,000 \times g\right.$ for $10 \mathrm{~min}$ at $\left.4{ }^{\circ} \mathrm{C}\right)$ and the supernatant was transferred to a new tube. A $200 \mu \mathrm{L}$ aliquot of supernatant was mixed well with $1 \mathrm{~mL} 20 \%$ TCA containing $0.5 \%$ TBA. This mixture was boiled at $95^{\circ} \mathrm{C}$ for $15 \mathrm{~min}$, quickly cooled on ice, centrifuged at $10,000 \times g$ for $5 \mathrm{~min}$, and then the supernatant was transferred to a cuvette. Finally, we measured the absorbance at $532 \mathrm{~nm}$ using a PerkinElmer Lambda 12 spectrophotometer (PerkinElmer, Shelton, CT, USA). A molar extinction coefficient of $155 \mathrm{~cm}^{-1} \mathrm{mM}^{-1}$ was used for MDA determination. The results were corrected for the experimental blank, and the MDA concentration was calculated as described by Lin et al. [17].

\subsection{Assessment of the Ability of LA to Chelate $\mathrm{Fe}^{2+}$}

We assessed the ability of LA to chelate $\mathrm{Fe}^{2+}$ using the colorimetric assay previously reported by Carter [18], with minor modifications. Briefly, $1.61 \mathrm{~mL}$ of each sample (MRS-cys) was diluted 1:30 (v/v) and then transferred into a 2-mL cuvette, with the addition of $150 \mu \mathrm{L} 0.30 \mathrm{mmol} / \mathrm{L} \mathrm{FeSO}$ and $0.5 \mathrm{~g} / \mathrm{L}$ LA. After a 5-min reaction time, we added $230 \mu \mathrm{L} 0.80 \mathrm{mmol} / \mathrm{L}$ ferrozine solution to each cuvette. In the control, the ferrozine solution was replaced by distilled water to correct for the unequal colors of the sample solutions. After $15 \mathrm{~min}$, we read the absorbance at $562 \mathrm{~nm}$ using a PerkinElmer Lambda 12 spectrophotometer (PerkinElmer, Shelton, CT, USA). The final results were expressed as mg EDTA equivalents/L, according to Santos and co-authors [19].

\subsection{Extraction of Cell-Associated Lipids and Gas Chromatography (GC) Analysis}

B. breve DSM 20213 was grown in MRS-cys and MRS-cys-LA, and then $50 \mathrm{~mL}$ of culture was centrifuged at $8000 \mathrm{rpm}$ for $10 \mathrm{~min}$, and the pellet was dissolved in $1 \mathrm{~mL}$ PBS buffer and transferred into a glass tube. Total lipids were extracted using $9 \mathrm{~mL}$ of chloroform/methanol $(2: 1, v / v)$ containing $5 \mu \mathrm{g} / \mathrm{mL}$ 10,12-tricosadiynoic acid (Sigma-Aldrich, St. Louis, MO, USA) for use as an internal standard. Tubes were incubated at room temperature for $2 \mathrm{~h}$, and then the lower phase containing the total lipids was transferred into a new tube and gently dried under nitrogen flow. Fatty acids were methylated by in situ transesterification with $0.5 \mathrm{~N}$ methanolic $\mathrm{NaOH}$ in methanol, followed by $14 \%$ boron trifluoride in methanol. After methylation, the lipid phase was extracted with $1 \mathrm{~mL}$ hexane.

Using an autosampler, the samples were injected into a gas chromatograph (model 7820A GC; Agilent Technologies, Santa Clara, CA, USA) equipped with a fused silica capillary column (CP-Sil 88, $100 \mathrm{~m} \times 0.25 \mathrm{~mm} \times 0.20 \mathrm{~mm}$; Agilent J\&W GC column) and a flame-ionization detector. A 25 to 1 split ratio was used for injection of $2 \mu \mathrm{L}$ hexane containing methyl esters. The carrier gas was ultrapure helium, and inlet pressure was maintained at $33.35 \mathrm{psi}$. The injector temperature was maintained at $250{ }^{\circ} \mathrm{C}$, and the detector temperature at $255^{\circ} \mathrm{C}$. The oven temperature was initially $70{ }^{\circ} \mathrm{C}$ (held for $4 \mathrm{~min}$ ), was increased by $10^{\circ} \mathrm{C} / \mathrm{min}$ to $180^{\circ} \mathrm{C}$ (held for $10 \mathrm{~min}$ ), and was then increased by $4{ }^{\circ} \mathrm{C} / \mathrm{min}$ to $240{ }^{\circ} \mathrm{C}$ (held for $25 \mathrm{~min}$ ), with a final run time of $60 \mathrm{~min}$. Peaks were identified using the Supelco 
37 Component FAME Mix (Sigma-Aldrich, St. Louis, MO, USA). CLA conversion was calculated as previously reported [20].

\section{Results}

\subsection{Gene Expression of B. breve DSM20213 in Response to LA Exposure}

We used an RNA-seq approach to examine the physiological and metabolic status of the B. breve DSM 20213 strain following in vitro exposure to $0.5 \mathrm{~g} / \mathrm{L}$ of LA. Gene expression was compared between the intestinal bacterium grown in MRS-cys-LA compared to in MRS-cys, to identify genes that were differentially expressed between the two conditions. Gene ontology (GO) classification and functional enrichment were performed, revealing that the differentially expressed genes could be classified into three ontology clusters: molecular biological function, cellular components, and biological process (Figures S1 and S2).

Overall, the highest numbers of DEGs were associated with "membrane," "membrane parts," and "catalytic activity". We also performed KEGG pathway classification (Figure 1) and functional enrichment.

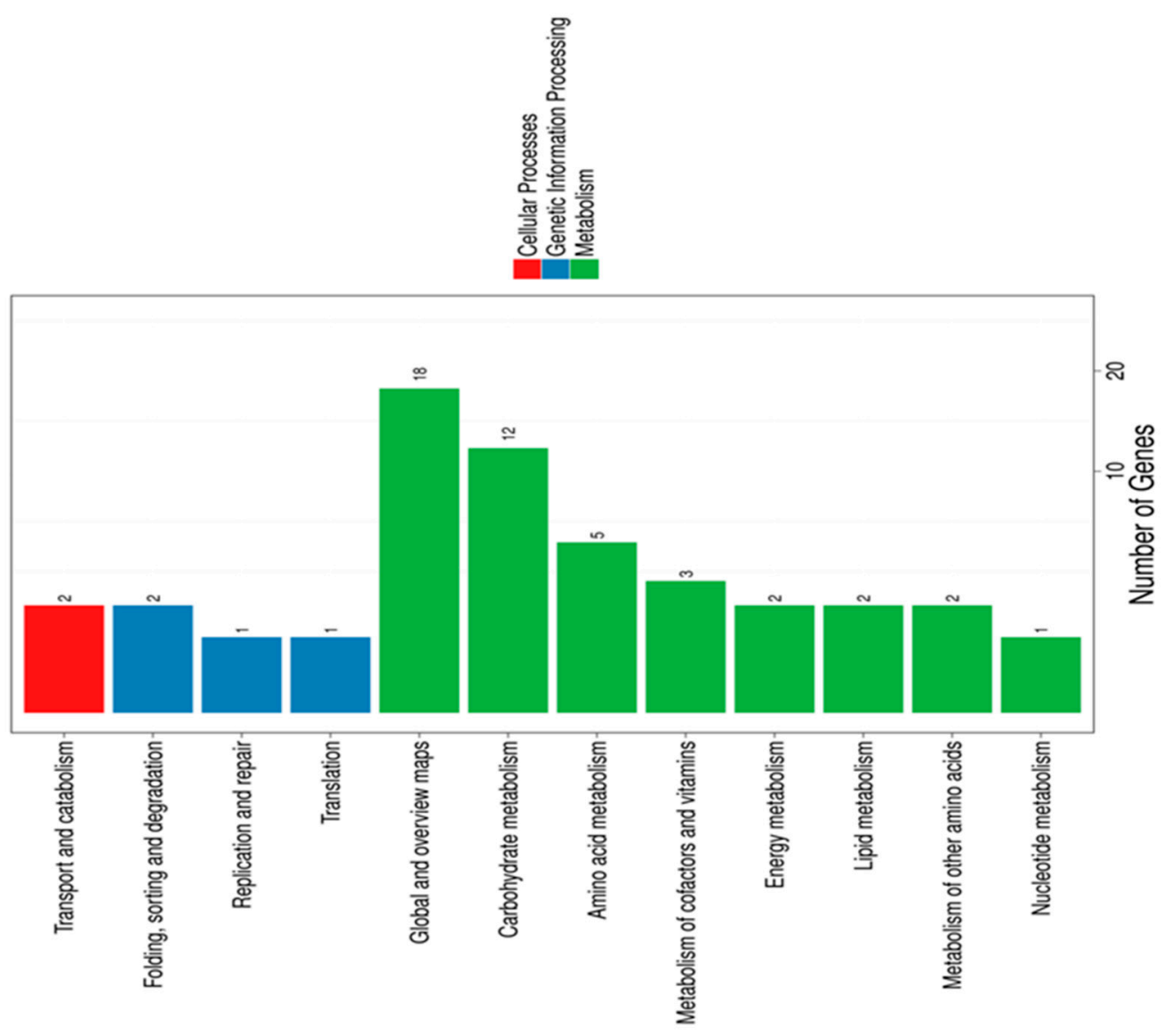

Figure 1. Kyoto Encyclopedia of Genes and Genomes (KEGG) pathway classification of differentially expressed genes. Genes were divided into three branches according to the biological pathways they participated in: cellular processes (red), genetic information processing (blue), and metabolism (green).

These analyses revealed that LA mainly impacted B. breve genes involved in carbohydrate and amino acid metabolism. Genes exhibiting less than a two-fold change were excluded from further analysis, leaving a total of 143 differentially regulated genes (53 upregulated and 90 downregulated) (Table S1). Gene annotation was achieved by searching the assigned locus tags in the NCBI Protein database for functionally characterized proteins displaying high similarity and/or mining locus tags 
associated with structural and functional annotations in the literature. In general, the most strongly upregulated genes were those involved in iron uptake systems, namely bfeUO and sifABCDE (Table 2).

Table 2. Expression changes in B. breve DSM 20213 following linoleic acid exposure.

\begin{tabular}{|c|c|c|}
\hline Locus Tag & Protein's Predicted Function & FC \\
\hline BBRE_1003 & $\begin{array}{l}\text { Secreted protein, probably } \\
\text { involved in iron uptake }\end{array}$ & 4 \\
\hline BBRE_1002 & $\begin{array}{c}\text { Membrane-spanning protein with } \\
\text { iron permease FTR1 family } \\
\text { domain }\end{array}$ & 3 \\
\hline BBRE_1006 & $\begin{array}{c}\text { Permease protein of } \mathrm{ABC} \\
\text { transporter system }\end{array}$ & 3 \\
\hline BBRE_1007 & $\begin{array}{l}\text { ATP-binding protein of ABC } \\
\text { transporter system }\end{array}$ & 3 \\
\hline BBRE_1005 & $\begin{array}{l}\text { Permease protein of } \mathrm{ABC} \\
\text { transporter system }\end{array}$ & 2 \\
\hline BBRE_1004 & Membrane-spanning protein & 2 \\
\hline BBRE_1008 & Hypothetical protein & 2 \\
\hline BBRE_1612 & $\begin{array}{l}\text { Hypothetical protein with methyl } \\
\text { transferase domain }\end{array}$ & 2 \\
\hline BBRE_1753 & $\begin{array}{c}\text { ATP-binding protein of } \mathrm{ABC} \\
\text { transporter system }\end{array}$ & 4 \\
\hline BBRE_0908 & Ferredoxin-NADP reductase & 2 \\
\hline BBRE_1404 & Cystathionine beta-lyase metC & 3 \\
\hline BBRE_1630 & Sulfatase family protein & -2 \\
\hline BBRE_1618 & $\begin{array}{c}\text { Macrolide-efflux protein, MFS } \\
\text { member }\end{array}$ & 1 \\
\hline BBRE_1621 & $\begin{array}{l}\text { Multidrug resistance protein B, } \\
\text { MFS member, bile efflux induced } \\
\text { upon bile salt exposure }\end{array}$ & 2 \\
\hline BBRE_1505 & WhiB protein, $\mathrm{WblE}$ & 3 \\
\hline BBRE_0144 & Transcriptional regulator & 2 \\
\hline BBRE_0799 & PTS system IIC component & -3 \\
\hline BBRE_0967 & $\begin{array}{l}\text { Oligopeptide transport system } \\
\text { permease protein, oppB }\end{array}$ & -2 \\
\hline BBRE_0966 & $\begin{array}{l}\text { Oligopeptide-binding protein, } \\
\text { oppA }\end{array}$ & -2 \\
\hline BBRE_0806 & $\begin{array}{l}\text { Ribonucleoside-diphosphate } \\
\text { reductase alpha chain }\end{array}$ & -2 \\
\hline BBRE_0137 & $\begin{array}{l}\text { Acetyl-/propionyl-CoA } \\
\text { carboxylase alpha chain }\end{array}$ & -2 \\
\hline BBRE_0138 & $\begin{array}{l}\text { Acetyl-/propionyl-CoA } \\
\text { carboxylase beta chain }\end{array}$ & -2 \\
\hline BBRE_0139 & $\begin{array}{l}\text { Type I multifunctional fatty acid } \\
\text { synthase }\end{array}$ & -2 \\
\hline BBRE_0798 & $\begin{array}{l}\text { Transcriptional regulator, GntR } \\
\text { family }\end{array}$ & -2 \\
\hline BBRE_0896 & $\begin{array}{l}\text { Lysyl-cardiolipin } \\
\text { synthase/Lysyl-transferase, } \mathrm{mprF}\end{array}$ & 2 \\
\hline BBRE_0949 & TadE-like protein & -3 \\
\hline BBRE_0946 & TadA-like protein & -1 \\
\hline BBRE_0948 & TadC-like protein & -1 \\
\hline BBRE_0750 & Cell division protein, Fic & 2 \\
\hline BBRE_0275 & $\begin{array}{l}\text { Histidine kinase sensor of } \\
\text { two-component system }\end{array}$ & -3 \\
\hline BBRE_0440 & 60-kDa chaperonin, GroEL & -2 \\
\hline BBRE_0182 & 10-kDa chaperonin, GroES & -2 \\
\hline BBRE_1435 & ATP-binding Mrp-like protein & 3 \\
\hline
\end{tabular}


The bfeUO system is responsible for ferric and ferrous import, and the sifABCDE system only for ferrous iron import. With regards to the bfeUO system, we found that LA exposure induced four-fold higher transcription of the BBRE_1003-encoded protein gene and three-fold higher transcription of the $B B R E \_1002$ gene, compared to control. In the sif $A B C D E$ cluster, LA exposure induced three-fold higher transcription of BBRE_1006 and BBRE_1007, and two-fold upregulation of BBRE_1004, BBRE_1005, and $B B R E \_1008$ genes. The highest levels of induction (fold-change of 4) were observed for the BBRE_1003 gene, a SAM-dependent methyltransferase (BBRE_1612), and an ABC transporter system gene (BBRE_1753). The function of BBRE_1612 is not well-known, but this gene is reportedly upregulated under iron limitation conditions [21]. Table 2 lists the genes involved in iron uptake, regulators, and S-Fe cluster assembly proteins. The ferredoxin-NADP reductase gene (BBRE_0908) was also upregulated. These proteins harbor a prosthetic flavin cofactor, and catalyze reversible electron exchange with NADPH and either flavodoxin or ferrodoxin. Reduced ferredoxin can serve as an electron donor for many enzymes, playing roles in several systems, including oxidative stress [22].

The addition of LA to $B$. breve growth medium also impacted the expressions of two genes involved in sulfur amino-acid metabolism: upregulation of the cystathionine $\beta$ lyase metC (BBRE_1404) and downregulation of a sulfatase family protein (BBRE_1630) (Table 2). Other differentially expressed genes were involved in membrane composition and pili formation. In terms of membrane modifications, LA apparently activated (fold-change of 2) the BBRE_1618 gene that encodes a macrolide efflux protein, and BBRE_1621 that encodes multidrug resistance protein $B$. These genes are strongly upregulated in the presence of cholic acid and oxgall [23], and represent the first microbial line of defense to protect the cell membrane from damaging compounds. Our results suggest that LA may be an inducer for this transport system, which could thus play a protective role in preserving membrane integrity.

LA exposure also influenced genes involved in regulation processes. The most highly expressed gene regulator was the WhiB-like protein WblE (BBRE_1505), which was originally isolated and identified by Averina et al. [24]. These iron-sulfur proteins have a redox-sensing function because of their four conserved cysteine residues. Averina et al. reported that this gene is upregulated under stress conditions, while the other two identified WhiB proteins exhibited no gene modulation. This line of evidence may implicate the WblE protein in sensing the external and intracellular redox state. Other upregulated genes included the $\mathrm{ClgR}$ regulator, which appears to be involved in solvent stress response [25], and BBRE_0144, which belongs to the xenobiotic response element family of transcriptional regulators (Table 2).

Overall, our results suggested that LA may have a negative regulatory effect on genes related to sugar transport, such as components of the PTS system and permease proteins of ABC transporter systems (Table S1). Of these, the PTS system IIC components were mostly downregulated. Such a reduction in sugar transport activity would impact carbon source utilization, consequently altering the production of ATP and important metabolic intermediates. Oligopeptide permease genes (opp gene cluster) were also downregulated—in particular, oppB (BBRE_0967) and oppA (BBRE_0966). Peptide transport systems play key roles in cell nutrition, as well as other processes, such as gene regulation expression, signaling, chemotaxis, conjugation, and competence development [26].

We also observed downregulated expression of genes involved in purine and pyrimidine metabolism. The ribonucleoside-diphosphate reductase system (BBRE_0806) exhibited two-fold lower expression in MRS-cys-LA than in MRS-cys. During cell division, this system is essential for converting ribonucleotides to deoxyribonucleotides, the precursors of DNA synthesis. Notably, downregulation of pyrimidine biosynthesis is a common strategy adopted by bifidobacteria to survive under stress conditions [27]. Our present findings regarding the DNA repair system suggest that LA does not induce DNA damage, based on the observed downregulation of DNA helicase II (BBRE_1548) (Table S1).

Interestingly, the presence of LA seemed to exert a negative effect on cell envelope. We observed reduced transcription of genes involved in lipid metabolism, including BBRE_0137, BBRE_0138, BBRE_0139, and BBRE_0798. We also observed downregulation of BBRE_0139, which is predicted 
to be a Type I multifunctional fatty acid synthase (fas). In B. breve UCC 2003 fas downregulation has been associated with reduced cell membrane integrity in response to bile [28]. This mechanism is often exploited by bacteria to survive under stress conditions [28,29]. Notably, LA reportedly modifies fatty acid composition in bifidobacteria cells [10].

Finally, RNA-seq analysis revealed that LA might also interfere with pili synthesis and thereby impact bacterial cell adhesion. We detected the downregulation of three predicted Tad genes. Bifidobacteria possess pili-adhesive and proteinaceous appendages that enable bacteria to adhere to host tissue [30]. Some of the genes encoding type IVb tight adherence (Tad) are expressed under several conditions, such as stress, or in the presence of other bacteria [31]. Our present results indicated that the TadE gene (BBRE_0949), which encodes one of the two pseudopilins and was identified in B. breve UCC2003 [30], exhibited three-fold lower expression in MRS-cys-LA than in MRS-cys. In contrast, TadA (BBRE_0946) and TadC (BBRE_0948) showed a fold-change of -1 . TadC represents an integral membrane protein that enables the secretion of the pilus subunits, together with TadA. We also detected upregulation of $B B R E \_0750$, with a fold-change of 2. This gene encodes the cell division protein Fic, which is involved in the catalysis of post-translational modification and regulation of bacterial filament. Members of the Fic protein family occur in taxonomically diverse bacteria and, interestingly, play a role in mediating bacterial responses to environmental stimuli. While we presently lack information regarding the role of the Fic protein family in modulating the shape of B. breve DSM 20213, optical microscope observation of this strain revealed reduced pleomorphism in MRS-cys-LA (Figure S4).

Among the sensor regulator genes, histidine kinase sensor (BBRE_0275) was downregulated with a fold-change of -3 , suggesting that LA may be sensed by bacterial cells via this type of specific sensor/regulator mechanism. We also observed downregulation (fold-change of -2 ) of general stress response systems, such as the groEL and groES chaperonins.

To validate the transcriptomic data, we performed real-time quantitative PCR (RT-qPCR) analysis of five different genes (data not shown). The RT-qPCR results were in agreement with the results of transcriptomic analysis $\left(r^{2}=0.904\right)$.

\subsection{LA Effect on Iron Metabolism}

Transcriptomic analysis revealed that the addition of LA to B. breve growth medium had an impact on genes involved in iron uptake. In Bifidobacterium longum strain BBMN68, two different Fe-S cluster assembly proteins and an iron complex transport system are upregulated under oxidative stress conditions [32]. In that context, only the suf gene was induced and strain BBMN68 activated biosynthesis of the Fe-S cluster-including proteins to restore proper biochemical metabolism. Our present results demonstrated that the most highly upregulated genes were those belonging to bfeUO and sif $A B C D E$. Moreover, the iron sulfur cluster-binding protein apbC (BBRE_1435) showed three-fold increased transcription with LA exposure compared to control. The higher gene expressions and the number of genes induced in the presence of LA in our study seemed to differ from those described in B. longum BBMN68 under oxidative conditions. The upregulation of several genes has also been described in B. breve UCC2003 under iron limitation conditions [21]. We conducted several experiments to exclude the involvement of LA in iron chelation. We first investigated the effect of iron salts on cell growth rate, with the rationale being to provide an extra source of iron to counteract an eventual iron deficiency in the medium. Under our experimental conditions, iron supplementation did not affect B. breve growth in MRS-cys (Figure 2).

We also examined the ability of LA to chelate iron, and our results excluded this hypothesis. The percentage of inhibition of complex formation did not differ between MRS-cys (90.744 mg EDTA eq/L) and MRS-cys-LA (90.969 mg EDTA eq/L). These results indicated that LA is not an iron chelator. Moreover, supplementation of the medium with iron did not improve the LA deconjugation, as there were no significant differences in the LA conversion $(55.3 \pm 3.3 \%$ in MRS-cys-LA; $58.5 \pm 2.4 \%$ in MRS-cys-LA FeSO $454.9 \pm 4.2 \%$ in MRS-cys-LA iron citrate; and $54 \pm 3.5 \%$ in MRS-cys-LA FeSO 4 iron 
citrate). Overall, our findings suggested that the induction of genes encoding iron uptake seemed to be correlated with a stress response because of the presence of LA in the medium.

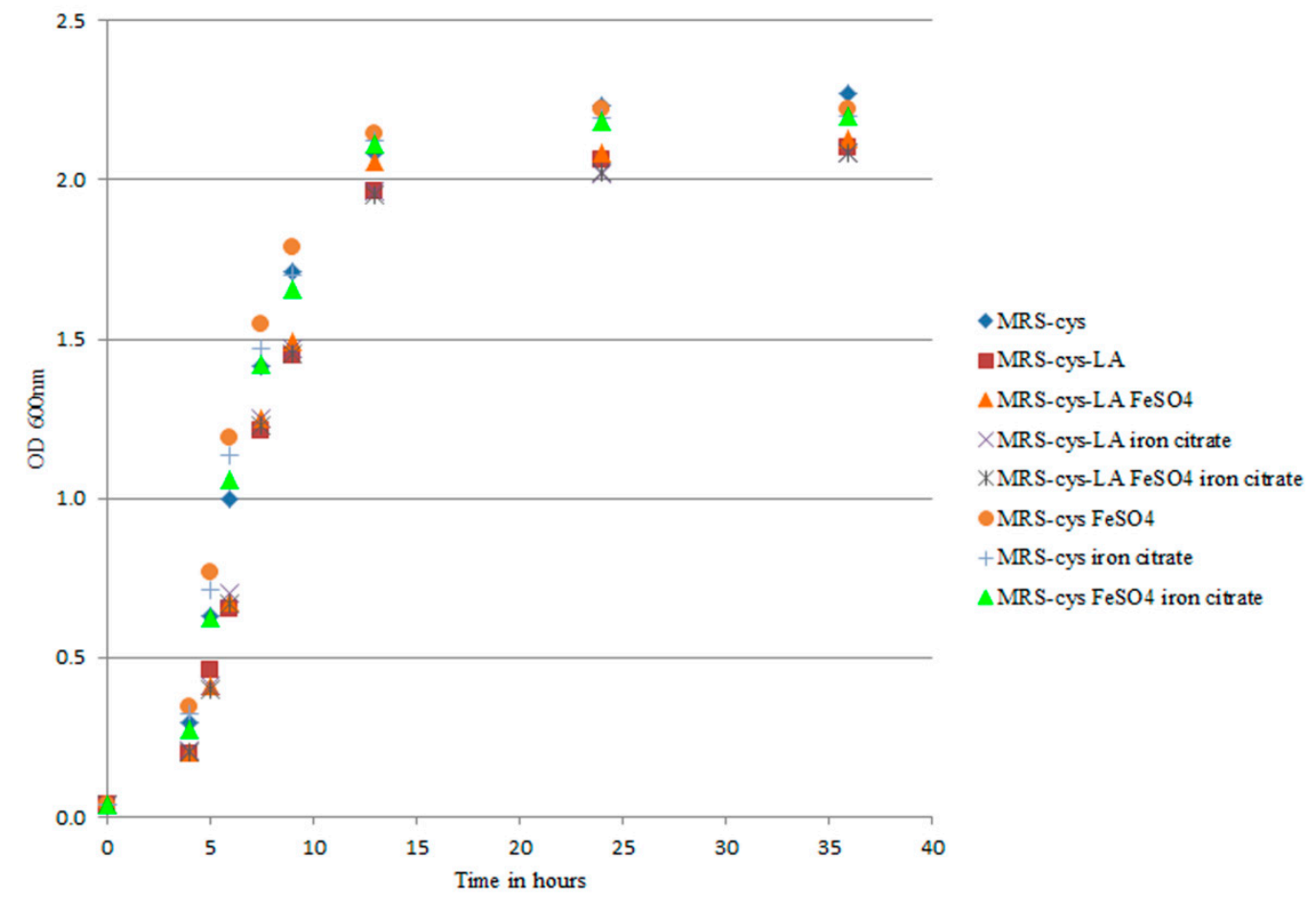

Figure 2. Growth curves of B. breve DSM 20213 grown in MRS-cys with iron sulfate, ferric citrate, and a 1:1 mix of both salts. The strain was exposed to $0.5 \mathrm{~g} / \mathrm{L}$ linoleic acid (LA), and the optical density was measured at $600 \mathrm{~nm}$. The growth of $B$. breve did not significantly differ among the tested experimental conditions $(p>0.05)$.

\subsection{LA Effect on ROS Production}

It is well established that LA is involved in oxidative damage in mammalian cells and tissue; however, this relationship remains unclear in bacteria. Our present results showed that LA exposure modulated the expressions of a number of $B$. breve genes involved in oxidative stress pathways, prompting us to further investigate the putative role of LA in ROS production. We found that the relative intracellular MDA content significantly differed $(p=0.0117)$ between bacterial cells grown in MRS-cys-LA (16.61 $\pm 4.03 \%$ ) versus those grown in MRS-cys (5.88 $\pm 1.27 \%)$.

Cysteine is associated with a protective effect against oxygen during anaerobic bifidobacteria growth [33]. To explore the actual impact of cysteine on the oxidative status of $B$. breve under our experimental conditions, we reduced the cysteine concentration in the medium down to $0 \mathrm{~g} / \mathrm{L}$ while maintaining an LA concentration of $0.5 \mathrm{~g} / \mathrm{L}$. The decreased cysteine content modified the trend of the growth curves, particularly in MRS-LA (Figure 3).

The part of the growth curve associated with the lag phase was most affected by changes in the medium. Changes in lag time are known to be a true consequence of stressful conditions [32]. We found that the lag phase was extended by approximately $8 \mathrm{~h}$ for $B$. breve growing in MRS-LA compared to in MRS $(p<0.05)$. Addition of LA did not affect the lag phase duration (approximately $5 \mathrm{~h}$ ) of B. breve in MRS-cys. In MRS-LA, B. breve DSM 20213 showed a reduced growth rate, with the cell number reaching $7 \log \mathrm{CFU} / \mathrm{mL}$ after $14 \mathrm{~h}$ of incubation, compared to $9 \log \mathrm{CFU} / \mathrm{mL}$ for this strain in MRS. On the other hand, when the strain was cultivated in MRS without LA, supplementation with a lower cysteine concentration did not affect the lag phase duration, confirming that this amino acid played a limited role in the growth of this strain (Figure S3). 


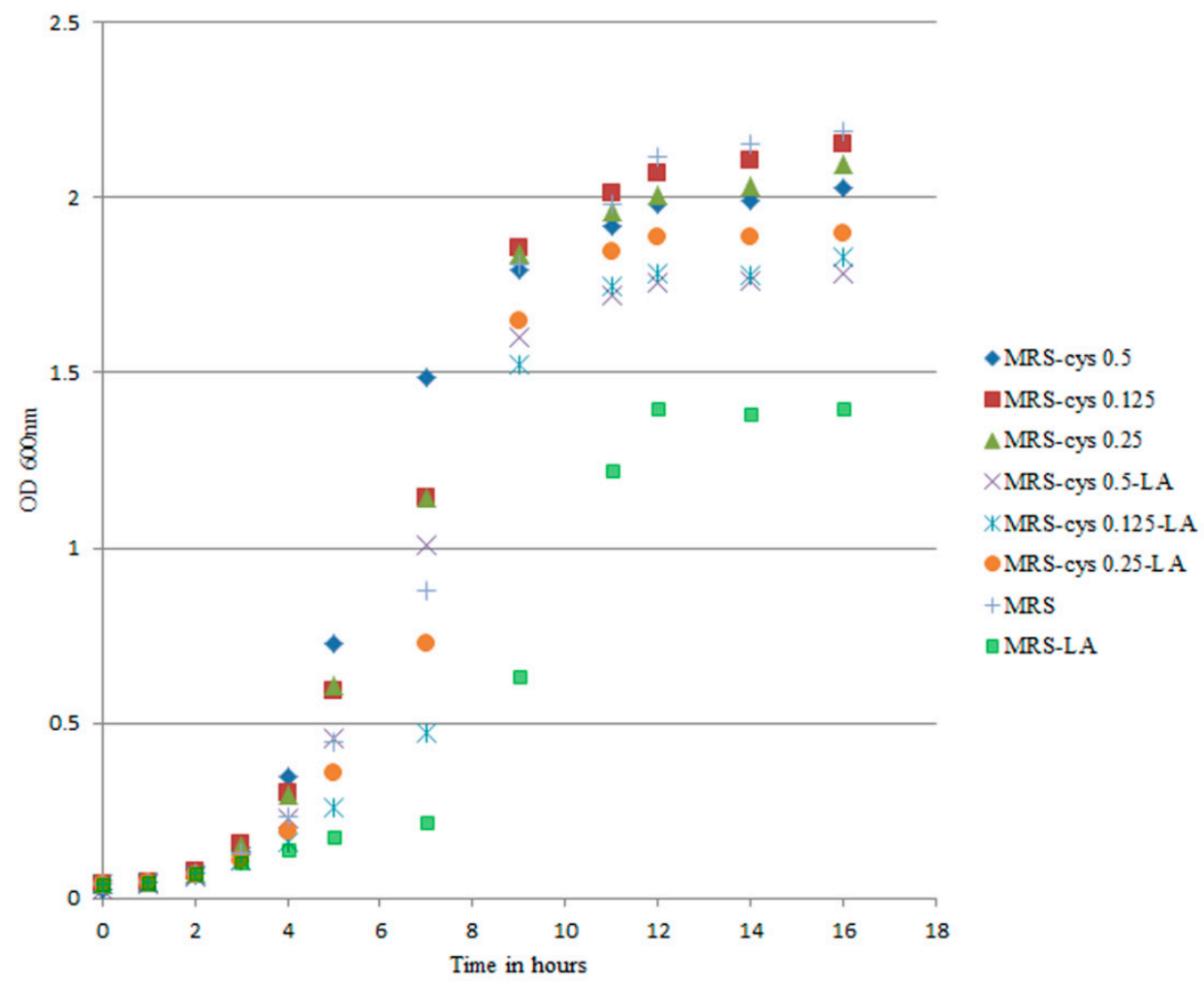

Figure 3. Growth curves of B. breve DSM 20213 grown in MRS-cys with different concentrations of cysteine. The linoleic acid (LA) concentration $0.5 \mathrm{~g} / \mathrm{L}$. Optical density was measured at $600 \mathrm{~nm}$. The growth of $B$. breve in MRS-LA was significantly different from that observed in MRS $(p<0.05)$.

Our results led us to speculate that cysteine may play a putative protective role against the negative effects of LA. To check this hypothesis, we determined the MDA content in MRS and MRS-LA, and found that the MDA level was significantly higher in MRS-LA (34.80 $\pm 6.90 \%)$ than in MRS $(8.21 \pm 2.92 \%)(p=0.0009)$. We also found that the relative MDA content significantly differed between bacteria grown in MRS-cys-LA $(16.61 \pm 4.03 \%)$ versus MRS-LA $(34.80 \pm 6.90 \%)(p=0.0264)$. Overall, our findings support that LA may be implicated in triggering oxidative stress in B. breve DSM 20213.

The high levels of MDA in MRS and MRS-LA suggested that the strain grown in the absence of cysteine exhibited higher expression of genes involved in oxidative response. Thus, we performed $\mathrm{q}-\mathrm{PCR}$ to determine the transcriptional level of the thioredoxin reductase gene. Thioredoxin reductase is considered to be one of the proteins responsible for maintaining a reduced intracellular environment. The expression of this gene was 1.64-fold higher in MRS-cys-LA than in MRS-cys, thus confirming the results of RNA-seq analysis. Conversely, this gene was upregulated by 2.46 -fold in MRS-LA compared with in MRS. The highest gene upregulation (5.26-fold) was observed in MRS-LA compared with MRS-cys-LA. These results seem to suggest that the presence of LA activated an oxidative stress response, and that this negative effect is likely mitigated by cysteine.

\section{Discussion}

In the present study, we applied a transcriptomic approach to examine how LA exposure influenced the intestinal B. breve strain DSM 20213. In recent decades, host-microbiota interaction has been among the most explored research fields because of its importance in host health and disease. Microbial populations in the gut produce a number of active compounds, and thereby mediate the impact of nutrients on host physiology. Bifidobacteria represent the dominant colonizers of the large intestine of infants during the first weeks of life [34], and play key roles in the human gut because of their glycan-degrading abilities [35] and their capacity to utilize human milk oligosaccharides (HMOs) [36,37]. After lipids and lactose, HMOs are the most abundant solid component in breast 
milk, but they do not represent nutritional value for infants because they are resistant to pancreatic digestion [38]. Bifidobacteria exploit HMOs as a selective nutrient, to increase their competitiveness in the gut environment. Accordingly, bifidobacteria strains are utilized as probiotics for infant health and well-being [39]. Among the different species of the Bifidobacterium genus, B. breve has been formulated for clinical trials in pediatrics [40-42] and used as a supplement in infant formulas [43,44].

Essential fatty acids, such as LA, are important diet constituents, particularly during early infant development; however, they cannot be synthesized by the body. Thus, nutrition research has focused on the development of infant formula that is nutritionally balanced and similar to human milk [45]. To date, there is scarce in vivo evidence regarding the impact of unsaturated fatty acids on gut microbiota composition and function [46], and the available data have mainly been collected in animal models. De Weirdt et al. reported that increased linoleic acid in the cecum might affect the level of Lactobacillus reuteri in mice fed a diet high in polyunsaturated fat [47]. Their findings suggest that linoleic acid reaches the distal gut, and is metabolized by specific populations within the gut microbial community. Several investigations of the effects of LA on bacterial cultures reveal that this fatty acid is toxic to many bacteria, which cannot grow in the presence of LA $[9,48]$. It has also been reported that long-chain fatty acids with higher degrees of unsaturation exert stronger inhibitory effects on bacterial growth compared to fatty acids of the same chain length but with lower numbers of double bonds [49]. One primary effect of LA on bacterial cells could be the modification of membrane composition, as reported by Fontes et al. [10]. They found that bacteria cells grown in MRS-cys-LA exhibited significantly decreased levels of stearic, myristic, and lactobacillic acids, but not of palmitic and oleic acids. Boyaval et al. further demonstrated that LA increases membrane permeability, blocking the cell growth of Propionibacterium freudenreichii subsp. shermanii, and causing increased $\mathrm{K}^{+}$efflux [50].

In the present study, we utilized RNA-seq methodology to assess the gene expression of $B$. breve DSM 20213 following exposure to LA, and to elucidate the in vitro effects of LA on the metabolic activities of the test organism. To our knowledge, this is the first study to show that LA can induce a multiple stress response in this microbial inhabitant of the infant gut.

Among the genes affected by LA, the most significant upregulation was detected for a cluster of genes related to the iron uptake system, which is often involved in bacterial responses to oxidative stress and adaptations to iron-limiting conditions [21,32]. B. breve DSM 20213 exhibited upregulation of both transcriptional units involved in iron uptake, although there was no differential expression of either thioredoxin reductase or glutaredoxin. In contrast, we observed upregulation of a ferredoxin NADP reductase gene encoding a protein with oxidoreductase activity, and the WblE gene that encodes a Fe-S protein involved in several stress responses, including the response to oxidative stress. To evaluate whether LA affected iron availability, we supplemented the growth medium of B. breve DSM 20213 with several different Fe sources and measured the bacterial growth rate. In this experiment, we also assessed the ability of LA to chelate $\mathrm{Fe}^{2+}$. Our results excluded that LA in MRS-cys was associated with any iron limitation effect, and excluded that LA had any direct involvement in bacterial CLA production as assessed by gas chromatography analysis.

Since our findings showed that LA exposure modulated several genes that are putatively involved in oxidative stress pathways, we explored the possibility that LA stimulated ROS production. We found that reactive oxygen species were significantly increased in $B$. breve cells grown in MRS-LA. The addition of cysteine to the medium seemed to protect bacterial cells against ROS-induced oxidative damage. Notably, we did not observe significant upregulation of genes encoding proteins with established roles in contrasting oxidative damages, possibly due to a protective action exerted by cysteine. Accordingly, thioredoxin reductase gene expression was higher in $B$. breve grown in the absence of cysteine compared to in the presence of cysteine, and this was the strongest effect recorded in MRS-LA.

Since LA exposure influenced genes and regulators involved in lipid metabolism, one could speculate that the cell membrane might be a target of LA action. Previous studies demonstrate that several kinds of stresses, including osmotic or acid stress, can prompt modifications in the bacterial cell membrane composition - particularly fatty acid chain length, saturation, and cyclopropanation-to 
decrease membrane permeability to oxidative free radicals and increase membrane resistance to lipid peroxidation [51]. We observed that LA induced downregulation of genes, such as the TadE gene, encoding type $\mathrm{IVb}$ tight adherence pili, which is in accordance with another transcriptional analysis showing reduced expression of these genes in response to stress conditions [52]. Pili are a key factor in bacterial adhesion and colonization of the host intestine [30]. As far as B. breve DSM 20213 is concerned, the involvement of pili in bacterial interaction with host tissue requires further clarification and, more specifically, the putative cell adhesion function of the TadE gene needs to be taken into consideration for future research. Despite the lack of evidence indicating that the cell filamentation protein fic is involved in morphological changes in bifidobacteria, RNA-seq analysis and observation with the optical microscope revealed a clear difference in B. breve DSM 20213 morphology—namely, a transition from a bifid shape to a rod shape.

Several species of bifidobacteria can convert LA into CLA, and the MCRA protein has been implicated in catalyzing the first step of CLA production in B. breve [8]. Our present results did not show any specific modulation of the mcra gene, suggesting that this enzyme was not involved in LA metabolization, which is in accordance with the findings of Raimondi et al. [6]. Along this line of evidence, O'Connell et al. [7] demonstrated that the MCRA protein of B. breve NCFB 2258 is an oleate hydratase that contributes to bifidobacterial solvent stress protection but not to CLA production. Indeed, Kishino et al. [53] proposed a multiple-step reaction mechanism for CLA production by the representative gut bacterium Lactobacillus plantarum. This pathway entails hydration, dehydration, and double-bond immigration and involves three different enzymes: CLA-HY, CLA-DH, and CLA-DC. Additionally, 10-hydroxy-12-octadecenoic acid has been identified as a key fatty acid intermediate of polyunsaturated fatty acid-saturation metabolism in L. plantarum [53]. Gao et al. [54] recently assessed the possibility that 10-hydroxy-12-octadecenoic acid, which is a product of MCRA activity in bifidobacteria, could represent an intermediate in bifidobacterial CLA generation. They demonstrated that $B$. breve can generate CLA using 10-hydroxy-cis-12 octadecenoic acid as a substrate. This aspect warrants further investigation, especially in light of recent findings indicating that L. plantarum multifunctional $\alpha$-enolase can directly convert 10-hydroxy-12-cis-octadecenoic acid into c9,t11-CLA through dehydration and isomerization reactions [55]. Although we presently have only a limited understanding of how bifidobacteria can convert LA into CLA, multiple or alternative mechanisms may be involved, as shown for lactobacilli.

Some evidence suggests that the ability to convert LA into CLA is strain-specific [6], and that the conversion rate changes depending on the growth conditions and matrix [10]. A recent study demonstrated that $B$. breve Ncimb702258 could produce CLA in skimmed milk, but the LA conversion rate was lower than in synthetic medium. Despite the positive effects of CLA on human health, the new evidence that LA exerts a significant toxic effect towards B. breve bacterial cells warrants reconsideration of the extent of milk formula supplementation with this fatty acid.

The present study has several limitations-most importantly, that it is an in vitro study. Although such an approach is very useful to gain knowledge on the overall bacterial metabolic responses, it is not sufficient to predict the behavior of B. breve DSM 20213 in the complex and dynamic gut environment. The interplay between different microbial populations, as well as between bacteria and the host, could affect multiple metabolic processes occurring in the intestinal environment, including LA conversion.

In conclusion, in our present study, we examined the transcriptional landscape of B. breve DSM 20213 in response to LA. The evidence reported in this work confirmed the in vitro toxicity of LA on this bacterial strain. There remains a need for further investigations, combining metagenomics and metabolomics approaches, to understand the impact of LA on microbial community functions and interactions with the host in the human infant gut.

Supplementary Materials: Supplementary materials can be found at http://www.mdpi.com/2076-2607/7/12/0710/ s1. 
Author Contributions: Conceptualization, V.P. and L.M.; methodology, A.S., M.L.C.; formal analysis, A.S., M.L.C., B.S., A.M. and G.R.; investigation, A.S, M.L.C.; data curation, A.S., M.L.C.; writing-original draft preparation, A.S., M.L.C.; writing—review \& editing, V.P.; supervision, L.M.

Funding: This research received no external funding.

Conflicts of Interest: The authors declare no conflict of interest. The funders had no role in the design of the study; in the collection, analyses, or interpretation of data; in the writing of the manuscript, or in the decision to publish the results.

\section{References}

1. Delplanque, B.; Gibson, R.; Koletzko, B.; Lapillonne, A.; Strandvik, B. Lipid Quality in Infant Nutrition. J. Pediatr. Gastroenterol. Nutr. 2015, 61, 1. [CrossRef]

2. Gorissen, L.; Raes, K.; Weckx, S.; Dannenberger, D.; Leroy, F.; De Vuyst, L.; De Smet, S. Production of conjugated linoleic acid and conjugated linolenic acid isomers by Bifidobacterium species. Appl. Microbiol. Biotechnol. 2010, 87, 2257-2266. [CrossRef]

3. Yang, B.; Chen, H.; Gu, Z.; Tian, F.; Ross, R.P.; Stanton, C.; Chen, Y.Q.; Chen, W.; Zhang, H. Synthesis of conjugated linoleic acid by the linoleate isomerase complex in food-derived lactobacilli. J. Appl. Microbiol. 2014, 117, 430-439. [CrossRef]

4. Lim, J.N.; Oh, J.J.; Wang, T.; Lee, J.S.; Kim, S.H.; Kim, Y.J.; Lee, H.G. Trans-11 18:1 vaccenic acid (TVA) has a direct anti-carcinogenic effect on MCF-7 human mammary adenocarcinoma cells. Nutrients 2014, 6, 627-636. [CrossRef]

5. Devillard, E.; McIntosh, F.M.; Duncan, S.H.; Wallace, R.J. Metabolism of Linoleic Acid by Human Gut Bacteria: Different Routes for Biosynthesis of Conjugated Linoleic Acid. J. Bacteriol. 2007, 189, 2566. [CrossRef]

6. Raimondi, S.; Amaretti, A.; Leonardi, A.; Quartieri, A.; Gozzoli, C.; Rossi, M. Conjugated Linoleic Acid Production by Bifidobacteria: Screening, Kinetic, and Composition. Biomed Res. Int. 2016, 2016, 8654317. [CrossRef]

7. O'Connell, K.J.; Motherway, M.O.; Hennessey, A.A.; Brodhun, F.; Ross, R.P.; Feussner, I.; Stanton, C.; Fitzgerald, G.F.; van Sinderen, D. Identification and characterization of an oleate hydratase-encoding gene from Bifidobacterium breve. Bioengineered 2013, 4, 313-321. [CrossRef]

8. Rosberg-Cody, E.; Liavonchanka, A.; Göbel, C.; Ross, R.P.; O'Sullivan, O.; Fitzgerald, G.F.; Feussner, I.; Stanton, C. Myosin-cross-reactive antigen (MCRA) protein from Bifidobacterium breve is a FAD-dependent fatty acid hydratase which has a function in stress protection. BMC Biochem. 2011, 12, 9. [CrossRef]

9. Koppová, I.; Lukáš, F.; Kopečný, J. Effect of fatty acids on growth of conjugated-linoleic-acids-producing bacteria in rumen. Folia Microbiol. 2006, 51, 291-293. [CrossRef]

10. Fontes, A.L.; Pimentel, L.; Rodríguez-Alcalá, L.M.; Gomes, A. Effect of Pufa Substrates on Fatty Acid Profile of Bifidobacterium breve Ncimb 702258 and CLA/CLNA Production in Commercial Semi-Skimmed Milk. Sci. Rep. 2018, 8, 15591. [CrossRef]

11. Coakley, M.; Ross, R.P.; Nordgren, M.; Fitzgerald, G.; Devery, R.; Stanton, C. Conjugated linoleic acid biosynthesis by human-derived Bifidobacterium species. J. Appl. Microbiol. 2003, 94, 138-145. [CrossRef] [PubMed]

12. Chomczynski, P.; Sacchi, N. Single-step method of RNA isolation by acid guanidinium thiocyanate-phenol-chloroform extraction. Anal. Biochem. 1987, 162, 156-159. [CrossRef]

13. Kim, D.; Langmead, B.; Salzberg, S.L. HISAT: A fast spliced aligner with low memory requirements. Nat. Methods 2015, 12, 357-360. [CrossRef] [PubMed]

14. Li, B.; Dewey, C.N. RSEM: Accurate transcript quantification from RNA-seq data with or without a reference genome. BMC Bioinform. 2011, 12, 323. [CrossRef] [PubMed]

15. Bottacini, F.; Zomer, A.; Milani, C.; Ferrario, C.; Lugli, G.A.; Egan, M.; Ventura, M.; van Sinderen, D. Global transcriptional landscape and promoter mapping of the gut commensal Bifidobacterium breve UCC2003. BMC Genomics 2017, 18, 991. [CrossRef]

16. Analysis of malondialdehyde, chlorophyll proline, soluble sugar, and glutathione content in Arabidopsis seedlin-BOC Sciences. Available online: https://www.bocsci.com/publication/192 (accessed on 3 October 2019). 
17. Lin, X.; Li, J.; Ma, S.; Liu, G.; Yang, K.; Tong, M.; Lin, D. Toxicity of TiO2 Nanoparticles to Escherichia coli: Effects of Particle Size, Crystal Phase and Water Chemistry. PLoS ONE 2014, 9, e110247. [CrossRef]

18. Carter, P. Spectrophotometric determination of serum iron at the submicrogram level with a new reagent (ferrozine). Anal. Biochem. 1971, 40, 450-458. [CrossRef]

19. Santos, J.S.; Alvarenga Brizola, V.R.; Granato, D. High-throughput assay comparison and standardization for metal chelating capacity screening: A proposal and application. Food Chem. 2017, 214, 515-522. [CrossRef]

20. Van Nieuwenhove, C.P.; Oliszewski, R.; González, S.N.; Pérez Chaia, A.B. Conjugated linoleic acid conversion by dairy bacteria cultured in MRS broth and buffalo milk. Lett. Appl. Microbiol. 2007, 44, 467-474. [CrossRef]

21. Lanigan, N.; Bottacini, F.; Casey, P.G.; O'Connell Motherway, M.; van Sinderen, D. Genome-Wide Search for Genes Required for Bifidobacterial Growth under Iron-Limitation. Front. Microbiol. 2017, 8, 964. [CrossRef]

22. Yeom, J.; Jeon, C.O.; Madsen, E.L.; Park, W. Ferredoxin-NADP+ Reductase from Pseudomonas putida Functions as a Ferric Reductase. J. Bacteriol. 2009, 191, 1472-1479. [CrossRef] [PubMed]

23. Ruiz, L.; Zomer, A.; O'Connell-Motherway, M.; van Sinderen, D.; Margolles, A. Discovering Novel Bile Protection Systems in Bifidobacterium breve UCC2003 through Functional Genomics. Appl. Environ. Microbiol. 2012, 78, 1123-1131. [CrossRef] [PubMed]

24. Averina, O.V.; Zakharevich, N.V.; Danilenko, V.N. Identification and characterization of WhiB-like family proteins of the Bifidobacterium genus. Anaerobe 2012, 18, 421-429. [CrossRef] [PubMed]

25. Zomer, A.; van Sinderen, D. Intertwinement of stress response regulons in Bifidobacterium breve UCC2003. Gut Microbes 2010, 1, 100-102. [CrossRef]

26. Lee, E.-M.; Ahn, S.-H.; Park, J.-H.; Lee, J.-H.; Ahn, S.-C.; Kong, I.-S. Identification of oligopeptide permease $(o p p)$ gene cluster in Vibrio fluvialis and characterization of biofilm production by oppA knockout mutation. FEMS Microbiol. Lett. 2004, 240, 21-30. [CrossRef]

27. An, H.; Douillard, F.P.; Wang, G.; Zhai, Z.; Yang, J.; Song, S.; Cui, J.; Ren, F.; Luo, Y.; Zhang, B.; et al. Integrated Transcriptomic and Proteomic Analysis of the Bile Stress Response in a Centenarian-originated Probiotic Bifidobacterium longum BBMN68. Mol. Cell. Proteomics 2014, 13, 2558-2572. [CrossRef]

28. Ruiz, L.; Sànchez, B.; Ruas-Madiedo, P.; de los Reyes-GavilÃàn, C.G.; Margolles, A. Cell envelope changes in Bifidobacterium animalis ssp. lactis as a response to bile. FEMS Microbiol. Lett. 2007, 274, 316-322. [CrossRef]

29. Roy, H. Tuning the properties of the bacterial membrane with aminoacylated phosphatidylglycerol. IUBMB Life 2009, 61, 940-953. [CrossRef]

30. O'Connell Motherway, M.; Zomer, A.; Leahy, S.C.; Reunanen, J.; Bottacini, F.; Claesson, M.J.; O’Brien, F.; Flynn, K.; Casey, P.G.; Moreno Munoz, J.A.; et al. Functional genome analysis of Bifidobacterium breve UCC2003 reveals type IVb tight adherence (Tad) pili as an essential and conserved host-colonization factor. Proc. Natl. Acad. Sci. USA 2011, 108, 11217-11222. [CrossRef]

31. Westermann, C.; Gleinser, M.; Corr, S.C.; Riedel, C.U. A Critical Evaluation of Bifidobacterial Adhesion to the Host Tissue. Front. Microbiol. 2016, 7, 1220. [CrossRef]

32. Zuo, F.; Yu, R.; Xiao, M.; Khaskheli, G.B.; Sun, X.; Ma, H.; Ren, F.; Zhang, B.; Chen, S. Transcriptomic analysis of Bifidobacterium longum subsp. longum BBMN68 in response to oxidative shock. Sci. Rep. 2018, 8, 17085. [CrossRef] [PubMed]

33. Muto, M.; Abe, F.; Yaeshima, T.; Iwatsuki, K. Effect of Enumeration Method on Bifidobacterium Cell Counts in Commercial Powder Products. Biosci. Microflora 2010, 29, 143-148. [CrossRef]

34. Turroni, F.; Milani, C.; Duranti, S.; Ferrario, C.; Lugli, G.A.; Mancabelli, L.; van Sinderen, D.; Ventura, M. Bifidobacteria and the infant gut: An example of co-evolution and natural selection. Cell. Mol. Life Sci. 2018, 75, 103-118. [CrossRef] [PubMed]

35. Milani, C.; Lugli, G.A.; Duranti, S.; Turroni, F.; Mancabelli, L.; Ferrario, C.; Mangifesta, M.; Hevia, A.; Viappiani, A.; Scholz, M.; et al. Bifidobacteria exhibit social behavior through carbohydrate resource sharing in the gut. Sci. Rep. 2015, 5, 15782. [CrossRef]

36. Gotoh, A.; Katoh, T.; Sakanaka, M.; Ling, Y.; Yamada, C.; Asakuma, S.; Urashima, T.; Tomabechi, Y.; Katayama-Ikegami, A.; Kurihara, S.; et al. Sharing of human milk oligosaccharides degradants within bifidobacterial communities in faecal cultures supplemented with Bifidobacterium bifidum. Sci. Rep. 2018, 8, 13958. [CrossRef]

37. Matsuki, T.; Yahagi, K.; Mori, H.; Matsumoto, H.; Hara, T.; Tajima, S.; Ogawa, E.; Kodama, H.; Yamamoto, K.; Yamada, T.; et al. A key genetic factor for fucosyllactose utilization affects infant gut microbiota development. Nat. Commun. 2016, 7, 11939. [CrossRef] 
38. Urashima, T.; Asakuma, S.; Leo, F.; Fukuda, K.; Messer, M.; Oftedal, O.T. The Predominance of Type I Oligosaccharides Is a Feature Specific to Human Breast Milk. Adv. Nutr. 2012, 3, 473S-482S. [CrossRef]

39. Bozzi Cionci, N.; Baffoni, L.; Gaggìa, F.; Di Gioia, D. Therapeutic Microbiology: The Role of Bifidobacterium breve as Food Supplement for the Prevention/Treatment of Paediatric Diseases. Nutrients 2018, 10, 1723. [CrossRef]

40. Underwood, M.A.; Davis, J.C.C.; Kalanetra, K.M.; Gehlot, S.; Patole, S.; Tancredi, D.J.; Mills, D.A.; Lebrilla, C.B.; Simmer, K. Digestion of Human Milk Oligosaccharides by Bifidobacterium breve in the Premature Infant. J. Pediatr. Gastroenterol. Nutr. 2017, 65, 449-455. [CrossRef]

41. Patole, S.; Keil, A.D.; Chang, A.; Nathan, E.; Doherty, D.; Simmer, K.; Esvaran, M.; Conway, P. Effect of Bifidobacterium breve M-16V Supplementation on Fecal Bifidobacteria in Preterm Neonates-A Randomised Double Blind Placebo Controlled Trial. PLoS ONE 2014, 9, e89511. [CrossRef]

42. Li, Y.; Shimizu, T.; Hosaka, A.; Kaneko, N.; Ohtsuka, Y.; Yamashiro, Y. Effects of Bifidobacterium breve supplementation on intestinal flora of low birth weight infants. Pediatr. Int. 2004, 46, 509-515. [CrossRef]

43. Abrahamse-Berkeveld, M.; Alles, M.; Franke-Beckmann, E.; Helm, K.; Knecht, R.; Köllges, R.; Sandner, B.; Knol, J.; Ben Amor, K.; Bufe, A. Infant formula containing galacto-and fructo-oligosaccharides and Bifidobacterium breve $\mathrm{M}-16 \mathrm{~V}$ supports adequate growth and tolerance in healthy infants in a randomised, controlled, double-blind, prospective, multicentre study. J. Nutr. Sci. 2016, 5, e42. [CrossRef] [PubMed]

44. Aloisio, I.; Prodam, F.; Giglione, E.; Bozzi Cionci, N.; Solito, A.; Bellone, S.; Baffoni, L.; Mogna, L.; Pane, M.; Bona, G.; et al. Three-Month Feeding Integration With Bifidobacterium Strains Prevents Gastrointestinal Symptoms in Healthy Newborns. Front. Nutr. 2018, 5, 39. [CrossRef] [PubMed]

45. Mendonça, M.A.; Araújo, W.M.C.; Borgo, L.A.; Alencar, E.d.R. Lipid profile of different infant formulas for infants. PLoS ONE 2017, 12, e0177812. [CrossRef] [PubMed]

46. Druart, C.; Bindels, L.B.; Schmaltz, R.; Neyrinck, A.M.; Cani, P.D.; Walter, J.; Ramer-Tait, A.E.; Delzenne, N.M. Ability of the gut microbiota to produce PUFA-derived bacterial metabolites: Proof of concept in germ-free versus conventionalized mice. Mol. Nutr. Food Res. 2015, 59, 1603-1613. [CrossRef]

47. De Weirdt, R.; Coenen, E.; Vlaeminck, B.; Fievez, V.; Van den Abbeele, P.; Van de Wiele, T. A simulated mucus layer protects Lactobacillus reuteri from the inhibitory effects of linoleic acid. Benef. Microbes 2013, 4, $299-312$. [CrossRef]

48. Alonso, L.; Cuesta, E.P.; Gilliland, S.E. Production of Free Conjugated Linoleic Acid by Lactobacillus acidophilus and Lactobacillus casei of Human Intestinal Origin. J. Dairy Sci. 2003, 86, 1941-1946. [CrossRef]

49. Yang, B.; Gao, H.; Stanton, C.; Ross, R.P.; Zhang, H.; Chen, Y.Q.; Chen, H.; Chen, W. Bacterial conjugated linoleic acid production and their applications. Prog. Lipid Res. 2017, 68, 26-36. [CrossRef]

50. Boyaval, P.; Corre, C.; Dupuis, C.; Roussel, E. Effects of free fatty acids on propionic acid bacteria. Lait 1995, 75, 17-29. [CrossRef]

51. Oberg, T.S.; Ward, R.E.; Steele, J.L.; Broadbent, J.R. Genetic and Physiological Responses of Bifidobacterium animalis subsp. lactis to Hydrogen Peroxide Stress. J. Bacteriol. 2013, 195, 3743-3751.

52. Duranti, S.; Turroni, F.; Lugli, G.A.; Milani, C.; Viappiani, A.; Mangifesta, M.; Gioiosa, L.; Palanza, P.; van Sinderen, D.; Ventura, M. Genomic Characterization and Transcriptional Studies of the Starch-Utilizing Strain Bifidobacterium adolescentis 22L. Appl. Environ. Microbiol. 2014, 80, 6080-6090. [CrossRef] [PubMed]

53. Kishino, S.; Park, S.B.; Takeuchi, M.; Yokozeki, K.; Shimizu, S.; Ogawa, J. Novel multi-component enzyme machinery in lactic acid bacteria catalyzing CC double bond migration useful for conjugated fatty acid synthesis. Biochem. Biophys. Res. Commun. 2011, 416, 188-193. [CrossRef] [PubMed]

54. Gao, H.; Yang, B.; Stanton, C.; Ross, R.P.; Zhang, H.; Chen, H.; Chen, W. Role of 10-hydroxy-cis-12-octadecenic acid in transforming linoleic acid into conjugated linoleic acid by bifidobacteria. Appl. Microbiol. Biotechnol. 2019. [CrossRef] [PubMed]

55. Ortega-Anaya, J.; Hernández-Santoyo, A. Production of bioactive conjugated linoleic acid by the multifunctional enolase from Lactobacillus plantarum. Int. J. Biol. Macromol. 2016, 91, 524-535. [CrossRef]

(C) 2019 by the authors. Licensee MDPI, Basel, Switzerland. This article is an open access article distributed under the terms and conditions of the Creative Commons Attribution (CC BY) license (http://creativecommons.org/licenses/by/4.0/). 